\title{
Suicide attempts in U.S. Army combat arms, special forces and combat medics
}

\author{
Robert J. Ursano ${ }^{1 *}$, Ronald C. Kessler², James A. Naifeh', Holly Herberman Mash', Carol S. Fullerton', \\ Tsz Hin Hinz Ng${ }^{1}$, Pablo A. Aliaga', Gary H. Wynn', Hieu M. Dinh', James E. McCarroll1', Nancy A. Sampson², \\ Tzu-Cheg Kao ${ }^{3}$, Michael Schoenbaum ${ }^{4}$, Steven G. Heeringa ${ }^{5}$, Murray B. Stein ${ }^{6,7}$ \\ and on behalf of the Army STARRS collaborators
}

\begin{abstract}
Background: The U.S. Army suicide attempt rate increased sharply during the wars in Iraq and Afghanistan. Risk may vary according to occupation, which significantly influences the stressors that soldiers experience.

Methods: Using administrative data from the Army Study to Assess Risk and Resilience in Servicemembers (Army STARRS), we identified person-month records for all active duty Regular Army enlisted soldiers who had a medically documented suicide attempt from 2004 through $2009(n=9650)$ and an equal-probability sample of control person-months $(n=153,528)$. Logistic regression analyses examined the association of combat occupation (combat arms [CA], special forces [SF], combat medic [CM]) with suicide attempt, adjusting for socio-demographics, servicerelated characteristics, and prior mental health diagnosis.

Results: In adjusted models, the odds of attempting suicide were higher in CA ( $O R=1.2$ [95\% Cl: 1.1-1.2]) and CM $(\mathrm{OR}=1.4$ [95\% Cl: $1.3-1.5])$, but lower in SF (OR = 0.3 [95\% Cl: 0.2-0.5]) compared to all other occupations. CA and CM had higher odds of suicide attempt than other occupations if never deployed (ORs $=1.1-1.5$ ) or previously deployed (ORs = 1.2-1.3), but not when currently deployed. Occupation was associated with suicide attempt in the first ten years of service, but not beyond. In the first year of service, primarily a time of training, CM had higher odds of suicide attempt than both CA (OR $=1.4$ [95\% Cl: 1.2-1.6]) and other occupations (OR $=1.5$ [95\% Cl: 1.3-1.7]). Discrete-time hazard functions revealed that these occupations had distinct patterns of monthly risk during the first year of service.
\end{abstract}

Conclusions: Military occupation can inform the understanding suicide attempt risk among soldiers.

Keywords: Suicide attempt, Military, Occupation

\section{Background}

Suicidal behavior among U.S. Army soldiers increased substantially during the wars in Iraq and Afghanistan, [1, 2] with the rates of suicide death more than doubling from $2001(9 / 100,000)$ through $2009(22 / 100,000)$ and surpassing the adjusted civilian rate in 2008 [3]. Although the Army has implemented a variety of screening [4-6] and prevention programs, [7] identifying soldiers at risk of suicide remains a significant challenge.

\footnotetext{
* Correspondence: robert.ursano@usuhs.edu

${ }^{1}$ Center for the Study of Traumatic Stress, Department of Psychiatry,

Uniformed Services University of the Health Sciences, 4301 Jones Bridge

Road, Bethesda, MD 20814, USA

Full list of author information is available at the end of the article
}

Research on military suicide has often emphasized the importance of deployment history, with mixed results [1, 3, 8-11]. Deployment experiences vary substantially depending on a soldier's military occupation. A metaanalysis found that suicidal outcomes were more strongly associated with particular combat experiences (e.g., killing, exposure to death) than with deployment in general, [12] suggesting that occupations characterized by direct combat exposure may have a higher suicide risk than other occupations $[13,14]$.

Soldiers with a combat arms (CA) occupation (e.g., infantry, airborne) have the highest likelihood of combat exposure, including frequent contact with enemy forces and increased risk of death and injury. CA 
soldiers tend to be at high risk for posttraumatic stress reactions, suicidality, and other mental health problems relative to other military occupations [15-17]. Special forces (SF) are elite, highly trained soldiers who engage in frequent, often unconventional warfare operations. Although SF is a branch of CA, it warrants distinct consideration. Soldiers who successfully complete the rigorous selection process and training for SF may have unique characteristics [18-20] that make them more resilient than other soldiers [21]. Combat medics (CM) are also of particular interest, as they serve dual roles as both soldiers and healthcare providers [22]. CM can experience direct combat exposure while embedded with infantry units [23, 24] and are also directly exposed to the severe injury and death of soldiers they attempt to save.

The relevance of occupation extends well beyond exposure to combat-related stressors. The content, duration, and stressors associated with training vary considerably by occupation. The first year of service is largely a time of training and carries particularly high risk for suicide attempts $[25,26]$. CM have intense performance demands during this time, including 16 weeks of Advanced Individual Training in which they must achieve proficiency equal to or greater than an emergency medical technician. The training demands on CA soldiers, while also intense, are very different in nature.

We examine the association of occupation with suicide attempts among enlisted soldiers in U.S. Army. Enlisted soldiers accounted for nearly 99\% of suicide attempts from 2004 through 2009 [26]. Using administrative data from the Army Study to Assess Risk and Resilience in Servicemembers (Army STARRS), [27] we focus on CA, $\mathrm{SF}$, and CM, three occupations with high likelihood of direct combat exposure. CA soldiers are traditionally a population of intense focus in military mental health research, however, less is known about the health and functioning of SF and CM soldiers. We also examined whether the association of occupation with suicide attempt varied by deployment status and time in service $[28,29]$.

\section{Methods \\ Sample}

This longitudinal, retrospective cohort study used data from the Army STARRS Historical Administrative Data Study (HADS), which integrates 38 Army and Department of Defense administrative data systems. The HADS includes deidentified individual-level person-month records for all soldiers on active duty between January 1 , 2004 and December 31, 2009 ( $n=1.66$ million) [30]. This component of Army STARRS was approved by the Institutional Review Boards of the Uniformed Services University of the Health Sciences, University of Michigan
Institute for Social Research, University of California, San Diego, and Harvard Medical School.

The analytic sample for the current investigation included all 9650 Regular Army enlisted soldiers who attempted suicide from 2004 through 2009 (excluding officers and activated Army National Guard and Army Reserve), plus an equal-probability sample of 153,523 control person-months. Data were analyzed using a discrete-time survival framework with person-month as the unit of analysis, [31] such that each month in the career of a soldier was treated as a separate observational record. Given that discrete-time survival coefficients can be estimated without bias when control person-months are randomly subsampled and weighted using the logic of case-control analysis, [32] we reduced computational intensity by selecting from the population an equal-probability 1:200 sample of control personmonths stratified by gender, rank, time in service, deployment status (never, currently, or previously deployed), and historical time. Control person-months excluded all soldiers with a documented suicide attempt or other non-fatal suicidal event (e.g., suicide ideation) [2] and person-months in which a soldier died. Each control person-month was assigned a weight of 200 to adjust for under-sampling.

\section{Measures \\ Suicide attempt}

Soldiers who attempted suicide were identified using administrative records from: the Department of Defense Suicide Event Report (DoDSER), [33] a DoD-wide surveillance mechanism that aggregates information on suicidal behaviors via a standardized form completed by medical providers at DoD treatment facilities; and ICD-9-CM diagnostic codes E950-E958 (indicating self-inflicted poisoning or injury with suicidal intent) from the Military Health System Data Repository (MDR), Theater Medical Data Store (TMDS), and TRANSCOM (Transportation Command) Regulating and Command and Control Evacuating System (TRAC ${ }^{2} E S$ ), which together provide healthcare encounter information from military and civilian treatment facilities, combat operations, and aeromedical evacuations (see Additional file 1: Table S1). We excluded suicide deaths and DoDSER records indicating only suicide ideation. The E959 code (late effects of a self-inflicted injury) was excluded, as it confounds the temporal relationships between the predictor variables and suicide attempt [34]. Records from different data systems were cross-referenced to ensure all cases represent unique soldiers. For soldiers with multiple suicide attempts, we selected the first attempt using a hierarchical classification scheme that prioritized DoDSER records due to that system's more extensive reporting requirements [2]. 


\section{Military occupation}

Occupational information for each person-month was obtained from the Defense Manpower Data Center. The current study focused on four occupational categories: combat arms (CA), special forces (SF), combat medics $(\mathrm{CM})$, and all other (AO) occupations (see Additional file 1: Table S2). Functional roles and duties of each occupation were examined to facilitate classification. CA included occupations that were identified, based on expert consensus, as those most typically exposed to direct combat. This includes some, but not all, of the occupations traditionally classified as combat arms [35, 36].

\section{Other predictors}

Socio-demographic (gender, current age, race, education, marital status), service-related (age at Army entry, time in service [ $\leq 1$ year, 2 years, 3-4 years, 5-10 years, $>10$ years], deployment status [never, currently, or previously deployed]) and previous mental health diagnosis variables were also drawn from Army/DoD administrative data systems (see Additional file 1: Table S1). The indicator variable for previous mental health diagnosis during Army service combined categories derived from ICD-9-CM codes (e.g., major depression, bipolar disorder, posttraumatic stress disorder, personality disorders), excluding postconcussion syndrome, tobacco use disorder, and supplemental V-codes that are not disorders (e.g., stressors/adversities, marital problems) when those were the only recorded mental health diagnoses (see Additional file 1: Table S3).

\section{Analysis}

All analyses were conducted using SAS version 9.3 [37]. We first examined the multivariate association of the four occupational categories with suicide attempt in logistic regression analyses that adjusted for sociodemographics and service-related variables. We then conducted a sensitivity analysis to examine the robustness of occupation as a predictor by adding to the model an indicator for any previous mental health diagnosis. Adjusting for socio-demographic and service-related variables, we then separately examined the interaction of occupation with deployment status (never, currently, or previously deployed) and time in service. Significant interactions were examined more closely through stratification. Logistic regression coefficients were exponentiated to obtain odds-ratios (OR) and 95\% confidence intervals (CI). Final model coefficients were used to generate a standardized risk estimate [38] (SRE; number of suicide attempters per 100,000 person-years) for each category of each predictor under the model assuming other predictors were at their sample-wide means. All logistic regression models included a dummy predictor for calendar month and year to control for increasing rates of suicide attempt from 2004 through 2009 [2]. Coefficients of other predictors can consequently be interpreted as averaged withinmonth associations based on the assumption that effects of other predictors do not vary over time.

We used discrete-time hazard functions and linear spline models to examine risk of suicide attempt as a function of time and occupation. Separate analyses for each occupational category estimated risk by months since entering service among soldiers in their first year. Splines (piecewise linear functions) were examined using chi-square difference tests, deviance, and the Akaike Information Criterion to test whether knots and additional linear segments improved model fit to assess nonlinearities in changes in risk by time in service.

\section{Results}

\section{Risk of suicide attempt by occupation}

Nearly one-quarter of enlisted soldiers were CA (23.3\%), $1.2 \%$ were $\mathrm{SF}$, and $4.8 \%$ were $\mathrm{CM}$, with $70.7 \%$ comprising AO. Out of 9650 total enlisted suicide attempters, $26.0 \%$ $(n=2506)$ were CA, $0.1 \%(n=16)$ were SF, $7.1 \%$ $(n=682)$ were CM, and $66.8 \%(n=6446)$ were AO. Adjusting for socio-demographic and service-related variables (not shown), the overall association of occupation with suicide attempt was significant $\left(\chi_{3}^{2}=126.2\right.$, $p<0.0001)$. Odds were higher for CA $(\mathrm{OR}=1.2[95 \%$ CI: $1.1-1.2])$ and $\mathrm{CM}(\mathrm{OR}=1.4$ [95\% CI: 1.3-1.5]) compared to $\mathrm{AO}$, whereas SF had lower odds $(\mathrm{OR}=0.3$ [95\% CI: 0.2-0.5]). The SRE was highest for CM (504/ 100,000 person-years [PY]), followed by CA (417/ $100,000 \mathrm{PY})$, and AO (357/100,000 PY). SF had the lowest SRE at 102/100,000 PY (Table 1). Pairwise analyses (not shown) indicated that $\mathrm{CM}$ were significantly more likely to attempt suicide than CA $(\mathrm{OR}=1.2[95 \% \mathrm{CI}$ : 1.1-1.3]), and this remained unchanged when comparing $\mathrm{CM}$ to $\mathrm{CA}$ among males only $(\mathrm{OR}=1.2$ [95\% CI: $1.1-$ 1.3]), which is important given that female soldiers were not permitted to have a CA or SF occupation at this time.

We next included an indicator for any prior mental health diagnosis while in the Army (see Additional file 1: Table S4). The association of occupation with suicide attempt remained significant $\left(\chi_{3}^{2}=96.2, p<0.0001\right)$. The ORs for CA $(\mathrm{OR}=1.2$ [95\% CI: 1.1-1.3]), SF $(\mathrm{OR}=0.5$ [95\% CI: 0.3-0.7]), and CM (OR = 1.3 [95\% CI: 1.2-1.4]) changed very little after accounting for prior mental health diagnosis. In a similar analysis among males the results were unchanged: $\mathrm{CA}(\mathrm{OR}=1.2$ [95\% CI: $1.2-$ 1.3]), SF (OR = 0.5 [95\% CI: 0.3-0.7]), and CM (OR = 1.3 [95\% CI: 1.2-1.4]) (see Additional file 1: Table S5). Among females the results for CM were also unchanged $(\mathrm{OR}=1.3$ [95\% CI: 1.2-1.5]). Given that inclusion of prior mental health diagnosis did not alter the influence 
Table 1 Multivariate association of military occupation with suicide attempt among Regular Army enlisted soldiers, adjusting for socio-demographic and service-related variables ${ }^{\mathrm{a}, \mathrm{b}}$

\begin{tabular}{|c|c|c|c|c|c|c|c|}
\hline & $\mathrm{OR}$ & $(95 \%$ Cl) & Cases $(n)$ & Total $(n)^{c}$ & Rate $^{d}$ & Pop \% ${ }^{\mathrm{e}}$ & $\mathrm{SRE}^{f}$ \\
\hline \multicolumn{8}{|l|}{ Occupation } \\
\hline Combat arms & $1.2^{*}$ & $(1.1-1.2)$ & 2506 & $7,159,106$ & 420 & 23.3 & 417 \\
\hline Special forces & $0.3^{*}$ & $(0.2-0.5)$ & 16 & 368,016 & 52 & 1.2 & 102 \\
\hline Combat medic & $1.4^{*}$ & $(1.3-1.5)$ & 682 & $1,470,882$ & 556 & 4.8 & 504 \\
\hline Other & 1.0 & - & 6446 & $21,716,246$ & 356 & 70.7 & 357 \\
\hline$x_{3}^{2}$ & \multicolumn{2}{|c|}{$126.2^{*}$} & & & & & \\
\hline
\end{tabular}

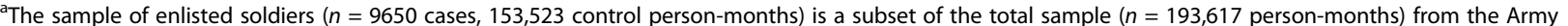
STARRS Historical Administrative Data Study (HADS). Control person-months were assigned a weight of 200 to adjust for under-sampling

${ }^{b}$ Logistic regression models included gender, age at Army entry, current age, race/ethnicity, education, marital status, time in service ( $\leq 1$ year, 2 years, 3-4 years,

5-10 years, $>10$ years), deployment status (never, currently, or previously deployed), and military occupation. The model also included a dummy predictor variable for calendar month and year to control for secular trends

'Total includes both cases (i.e., soldiers with a suicide attempt) and control person-months

${ }^{d}$ Rate per 100,000 person-years, calculated based on $n_{1} / n_{2}$, where $n_{1}$ is the unique number of soldiers within each category and $n_{2}$ is the annual number of person-years, not person-months, in the population ( $n=3.08$ million)

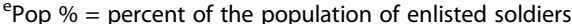

${ }^{\mathrm{f}} \mathrm{SRE}=$ Standardized risk estimates (suicide attempters per 100,000 person-years) were calculated assuming other predictors were at their sample-wide means ${ }^{*} p<0.05$

of occupation on risk of suicide attempt, we did not include mental health diagnosis in subsequent analyses. SF soldiers were excluded from subsequent analyses owing to their small numbers.

In separate analyses that adjusted for socio-demographic and service-related predictors, the two-way interactions of occupation with deployment status $\left(\chi^{2}{ }_{4}=43.8, p<0.0001\right)$ and time in service $\left(\chi_{8}^{2}=47.2, p<0.0001\right)$ were significant. Their three-way interaction was non-significant.

We stratified by deployment status and examined occupation in separate models that adjusted for the sociodemographic and service-related covariates. The association of occupation with suicide attempt was significant among never deployed $\left(\mathrm{X}_{2}^{2}=67.2, p<0.0001\right)$ and previously deployed $\left(\mathrm{X}_{2}^{2}=32.8, p<0.0001\right)$, but not among currently deployed $\left(\mathrm{X}_{2}^{2}=4.5, p=0.10\right)$. CA had higher odds of suicide attempt than $\mathrm{AO}$ in those never deployed $(\mathrm{OR}=1.1$ [95\% CI: $1.0-1.2] ; \mathrm{SRE}=610 /$
$100,000 \mathrm{PY}$ ) and previously deployed (OR $=1.3[95 \%$ CI: $1.2-1.4]$; SRE $=358 / 100,000$ PY). CM also had higher odds than $\mathrm{AO}$ in never deployed (OR $=1.5[95 \%$ CI: $1.3-1.6]$; SRE $=801 / 100,000 \mathrm{PY})$ and previously deployed $(\mathrm{OR}=1.2$ [95\% CI: $1.0-1.5]$; SRE $=352 / 100,000$ PY) (Table 2; see Additional file 1: Table S6 for supplemental counts and rates by occupation and deployment status). In pairwise analyses $\mathrm{CM}$ had significantly higher odds relative to $\mathrm{CA}$ in those never deployed $(\mathrm{OR}=1.3$ [95\% CI: 1.2-1.5]), but not in those previously deployed. Stratifying by occupation, deployment status was associated with suicide attempt among CA $\left(\chi_{2}^{2}=367.0, p<0.0001\right), \mathrm{CM}\left(\chi_{2}^{2}=29.8, p<0.0001\right)$, and AO $\left(\mathrm{X}^{2}{ }_{2}=378.1, p<0.0001\right)$. Among CA, those never deployed (OR $=3.3$ [95\% CI: $2.8-3.8]$ ) or previously deployed (OR = 3.8 [95\% CI: 3.3-4.4]) had higher odds than currently deployed, and previously deployed CA had higher odds than those never deployed

Table 2 Multivariate associations of military occupation with suicide attempt among Regular Army enlisted soldiers stratified by deployment status ${ }^{\mathrm{a}, \mathrm{b}}$

\begin{tabular}{|c|c|c|c|c|c|c|c|c|c|}
\hline & \multicolumn{9}{|c|}{ Deployment Status } \\
\hline & \multicolumn{3}{|c|}{$\begin{array}{l}\text { Never Deployed } \\
(n=67,336)\end{array}$} & \multicolumn{3}{|c|}{$\begin{array}{l}\text { Currently Deployed } \\
(n=36,460)\end{array}$} & \multicolumn{3}{|c|}{$\begin{array}{l}\text { Previously Deployed } \\
(n=57,521)\end{array}$} \\
\hline & $\overline{O R}$ & $(95 \% \mathrm{Cl})$ & $\mathrm{SRE}^{\mathrm{C}}$ & $\overline{O R}$ & $(95 \% \mathrm{Cl})$ & $\mathrm{SRE}^{\mathrm{C}}$ & $\overline{O R}$ & $(95 \% \mathrm{Cl})$ & $\mathrm{SRE}^{\mathrm{C}}$ \\
\hline \multicolumn{10}{|l|}{ Occupation } \\
\hline Combat arms & $1.1^{*}$ & $(1.0-1.2)$ & 610 & 1.0 & $(0.9-1.2)$ & 159 & $1.3^{*}$ & $(1.2-1.4)$ & 358 \\
\hline Combat medic & $1.5^{*}$ & $(1.3-1.6)$ & 801 & $1.3^{*}$ & $(1.0-1.8)$ & 208 & $1.2^{*}$ & $(1.0-1.5)$ & 352 \\
\hline Other & 1.0 & - & 546 & 1.0 & - & 155 & 1.0 & - & 283 \\
\hline$x_{2}^{2}$ & \multicolumn{3}{|c|}{$67.2^{*}$} & \multicolumn{3}{|c|}{4.5} & \multicolumn{2}{|c|}{$32.8^{*}$} & \\
\hline
\end{tabular}

${ }^{a}$ The sample of enlisted soldiers ( $n=9650$ cases, 153,523 control person-months) is a subset of the total sample ( $n=193,617$ person-months) from the Army STARRS Historical Administrative Data Study (HADS). Control person-months were assigned a weight of 200 to adjust for under-sampling

${ }^{b}$ Logistic regression models included gender, age at Army entry, current age, race/ethnicity, education, marital status, time in service ( $\leq 1$ year, 2 years, 3-4 years, $5-10$ years, $>10$ years), and military occupation. The models also included a dummy predictor variable for calendar month and year to control for secular trends ${ }^{\mathrm{c}} \mathrm{SRE}=$ standardized risk estimates (suicide attempters per 100,000 person-years) were calculated assuming other predictors were at their sample-wide means ${ }^{*} p<0.05$ 
$(\mathrm{OR}=1.2[95 \% \mathrm{CI}: 1.0-1.3])$. Similarly, among CM, never deployed $(\mathrm{OR}=1.9$ [95\% CI: 1.4-2.6]) or previously deployed $(\mathrm{OR}=2.4$ [95\% CI: 1.7-3.2]) had higher odds of suicide attempt than those currently deployed. However, there was no difference between CM who were never deployed and previously deployed. Among AO, never deployed $(\mathrm{OR}=2.1$ [95\% CI: 1.9-2.3]) and previously deployed $(\mathrm{OR}=2.5$ [95\% CI: 2.3-2.8]) had higher odds than those currently deployed, and those previously deployed had higher odds than those never deployed $(\mathrm{OR}=1.2$ [95\% CI: 1.1-1.3]) (see Additional file 1: Table S7a and S7b for pairwise analyses by occupation and deployment status).

We stratified the sample by time in service and examined occupation in similarly adjusted models. The association of occupation with suicide attempt was significant among soldiers with $\leq 10$ years of service $(\leq 1$ year, $\chi_{2}^{2}=44.9, p<0.0001 ; 2$ years, $\chi_{2}^{2}=19.1, p<0.0001 ; 3-$ 4 years, $X_{2}^{2}=18.7, p<0.0001 ; 5-10$ years, $\chi_{2}^{2}=25.4$, $p<0.0001$ ), but not among those with more than 10 years of service $\left(\mathrm{X}_{2}^{2}=3.7, p=0.16\right)$. CA did not differ from $\mathrm{AO}$ during their first year of service, but had significantly higher odds of suicide attempt at 2 years (OR $=1.2[95 \%$ CI: 1.0-1.3]), 3-4 years (OR = 1.2 [95\% CI: $1.1-1.3]$ ), and $5-10$ years $(\mathrm{OR}=1.4$ [95\% CI: $1.2-1.5])$ of service. $\mathrm{CA}$ were at greatest risk in their first year of service (931/ 100,000 PY), with risk decreasing monotonically as time in service increased to more than 10 years $(76 / 100,000$ PY). In contrast, CM had significantly higher odds than AO throughout their first 4 years of service ( $\leq 1$ year, $\mathrm{OR}=1.5$ [95\% CI: $1.3-1.7] ; 2$ years, OR $=1.4$ [95\% CI: 1.2-1.7]; 3-4 years, OR = 1.3 [95\% CI: 1.1-1.6]), but did not differ after 4 years of service. Risk was highest for CM in their first year of service (1313/100,000 PY) and decreased monotonically as time in service increased to more than 10 years $(98 / 100,000$ PY). AO had the lowest risk of suicide attempt, ranging from 868/100,000 PY during the first year of service to $69 / 100,000$ PY in those with more than 10 years of service (Table 3; see Additional file 1: Table S8 for supplemental counts and rates by occupation and time in service). Importantly, in pairwise analyses CM had higher odds of suicide attempt than CA in the first year of service $(\mathrm{OR}=1.4$ [95\% CI: 1.2-1.6]), which remained unchanged when limiting the analysis to males $(\mathrm{OR}=1.4$ [95\% CI: $1.2-$ 1.7]), but CM did not differ significantly from CA in subsequent years of service. When stratifying by occupation, time in service was associated with suicide attempt among $\mathrm{CA}\left(\mathrm{X}_{4}^{2}=88.8, p<0.0001\right), \mathrm{CM}$ $\left(\chi_{2}^{2}=45.4, p<0.0001\right)$, and AO $\left(\chi_{2}^{2}=448.4\right.$, $p<0.0001)$. Among CA, odds of suicide attempt did not differ between the first and second year of service, but decreased significantly thereafter. Among CM and AO there was a consistent, significant decrease in the odds of suicide attempt as time in service increased (see Additional file 1: Table S9a and S9b for pairwise analyses by occupation and time in service).

\section{Monthly risk during the first year of service by occupation}

Hazard functions and linear spline models suggest that the pattern of monthly suicide attempt risk during the first year of service varied by occupation (Fig. 1). CA had two distinct periods of elevated risk in the second month (97/100,000 person-months) and eighth month (90/100,000 person-months), with a period of decreased risk in between that dropped to a low of $37 / 100,000$ person-months in the fifth month of service. Although risk among $\mathrm{CM}$ was also greatly elevated during the second month (174/100,000 person-months), it remained elevated through the fifth and sixth months (217-221/ 100,000 person-months) before beginning a steady decline to $47 / 100,000$ person-months in the 12 th month of service. Among AO there was a similar peak in risk

Table 3 Multivariate associations of military occupation with suicide attempt among Regular Army enlisted soldiers stratified by time in service ${ }^{a, b}$

\begin{tabular}{|c|c|c|c|c|c|c|c|c|c|c|c|c|c|c|c|}
\hline & \multicolumn{15}{|c|}{ Time in Service } \\
\hline & \multicolumn{3}{|c|}{$\begin{array}{l}1 \text { Year } \\
(n=25,786)\end{array}$} & \multicolumn{3}{|c|}{$\begin{array}{l}2 \text { Years } \\
(n=22,162)\end{array}$} & \multicolumn{3}{|c|}{$\begin{array}{l}3-4 \text { Years } \\
(n=36,155)\end{array}$} & \multicolumn{3}{|c|}{$\begin{array}{l}5-10 \text { Years } \\
(n=42,701)\end{array}$} & \multicolumn{3}{|c|}{$\begin{array}{l}>10 \text { Years } \\
(n=34,513)\end{array}$} \\
\hline & $\overline{O R}$ & $(95 \% \mathrm{Cl})$ & $\mathrm{SRE}^{\mathrm{C}}$ & $\overline{O R}$ & $(95 \% \mathrm{Cl})$ & $\mathrm{SRE}^{\mathrm{C}}$ & $\overline{\mathrm{OR}}$ & $(95 \% \mathrm{Cl})$ & $\mathrm{SRE}^{\mathrm{C}}$ & $\overline{\mathrm{OR}}$ & $(95 \% \mathrm{Cl})$ & $\mathrm{SRE}^{\mathrm{C}}$ & $\overline{O R}$ & $(95 \% \mathrm{Cl})$ & $\mathrm{SRE}^{\mathrm{C}}$ \\
\hline \multicolumn{16}{|l|}{ Occupation } \\
\hline Combat arms & 1.1 & $(1.0-1.2)$ & 931 & $1.2^{*}$ & $(1.0-1.3)$ & 657 & $1.2^{*}$ & $(1.1-1.3)$ & 453 & $1.4^{*}$ & $(1.2-1.5)$ & 279 & 1.1 & $(0.9-1.4)$ & 76 \\
\hline Combat medic & $1.5^{*}$ & $(1.3-1.7)$ & 1313 & $1.4^{*}$ & $(1.2-1.7)$ & 795 & $1.3^{*}$ & $(1.1-1.6)$ & 494 & 1.2 & $(1.0-1.5)$ & 253 & 1.4 & $(1.0-2.1)$ & 98 \\
\hline Other & 1.0 & - & 868 & 1.0 & - & 565 & 1.0 & - & 378 & 1.0 & - & 207 & 1.0 & - & 69 \\
\hline$x_{2}^{2}$ & \multicolumn{3}{|c|}{$44.9^{*}$} & \multicolumn{3}{|c|}{$19.1^{*}$} & \multicolumn{3}{|c|}{$18.7^{*}$} & \multicolumn{3}{|c|}{$25.4^{*}$} & \multicolumn{3}{|c|}{3.7} \\
\hline
\end{tabular}

${ }^{a}$ The sample of enlisted soldiers ( $n=9650$ cases, 153,523 control person-months) is a subset of the total sample ( $n=193,617$ person-months) from the Army STARRS Historical Administrative Data Study (HADS). Control person-months were assigned a weight of 200 to adjust for under-sampling

${ }^{b}$ Logistic regression models included gender, age at Army entry, current age, race/ethnicity, education, marital status, deployment status (never, currently, or previously deployed), and military occupation. The models also included a dummy predictor variable for calendar month and year to control for secular trends 'SRE = standardized risk estimates (suicide attempters per 100,000 person-years) were calculated assuming other predictors were at their sample-wide means ${ }^{*} p<0.05$ 

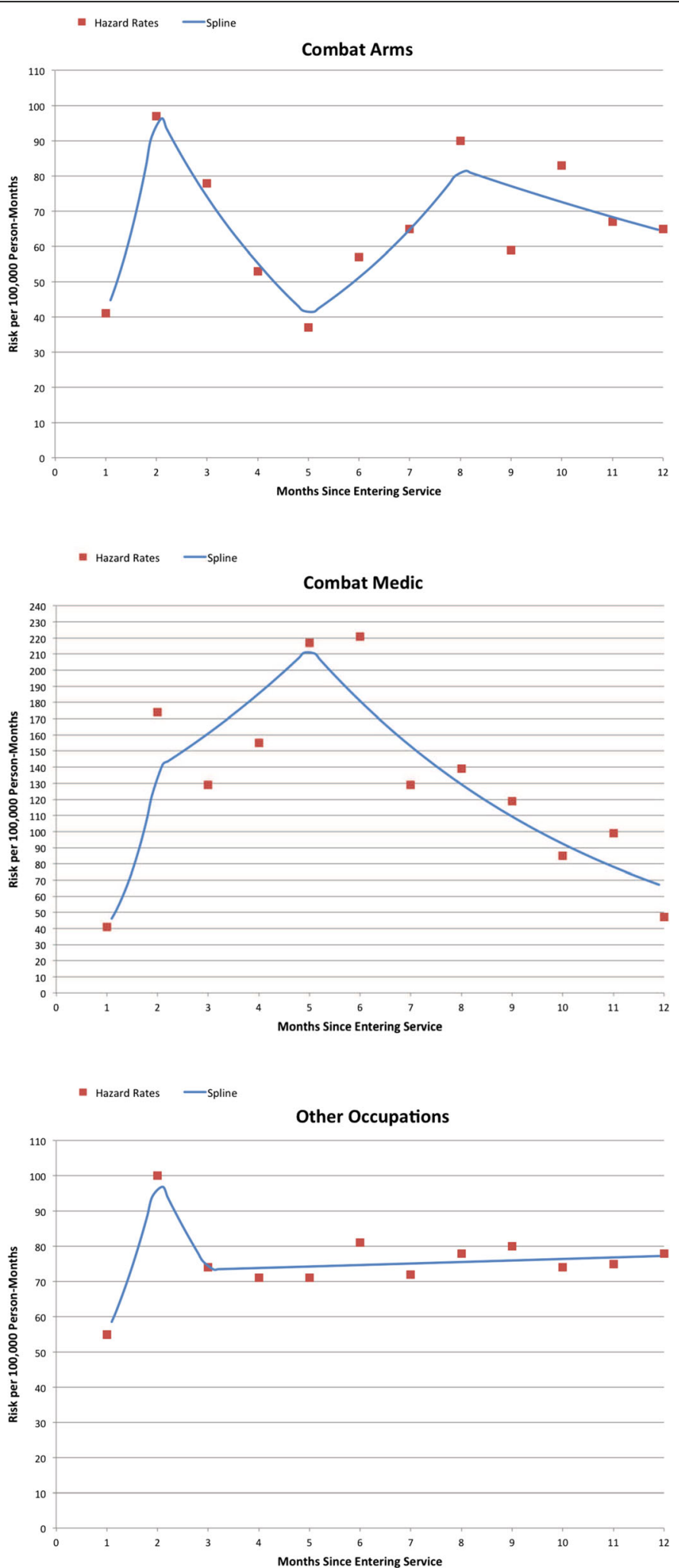

Fig. 1 Monthly risk of suicide attempt by military occupation and among Regular Army enlisted soldiers in their first year of service ${ }^{1,2}$ ${ }^{1}$ The sample of enlisted soldiers in their first year of service (combat arms, $n=6,853$; combat medic, $n=1,450$; other, $n=17,483$ ) is a subset of the total sample of enlisted soldiers ( $n=163,173$ person-months) from the Army STARRS Historical Administrative Data Study (HADS). Control person-months were assigned a weight of 200 to adjust for under-sampling. ${ }^{2}$ Monthly risk based on hazard rates and linear spline models 
during the second month (100/100,000 person-months), which then sharply declined and remained relatively stable from the third (74/100,000 person-months) to the 12th month (78/100,000 person-months).

\section{Discussion}

We found that soldiers with a combat occupation had higher risk of suicide attempt than other soldiers, with the exception of SF. CA soldiers accounted for $26.0 \%$ of all enlisted suicide attempters, with an overall standardized risk of 417/100,000 PY (compared to 357/ 100,000 PY for other occupations). CM soldiers, while accounting for only $7.1 \%$ of attempters, had the highest standardized risk (504/100,000 PY). They also were more likely to attempt suicide than $\mathrm{CA}$, a finding that persisted in males. The significant but modestly elevated odds for $C A$ and $C M$ versus $A O$ persisted even after adjusting for previous mental health diagnosis. The unique aspects of military service, particularly during wartime, make it difficult to draw direct comparisons with the literature on suicide risk among civilian occupations. $\mathrm{CA}$ and $\mathrm{CM}$ soldiers share some similarities with police officers and emergency medical technicians, respectfully, two civilian occupational groups for which there is some evidence of elevated suicide risk [39].

Despite having an occupation that typically includes intense combat exposure over multiple deployments, SF accounted for only 16 suicide attempters from 2004 to 2009 , with a standardized risk (102/100,000 PY) considerably lower than other occupations. The resilience of SF [21] may result from rigorous selection, intense training, [40] strong unit cohesion, [41] or psychological and biological characteristics [18-20]. Research on SF is lacking, and efforts to reduce suicide risk and mental healthcare stigma remain high priorities [42, 43]. Future Army STARRS studies with administrative data beyond 2009 will allow further examination of SF.

The higher risk for CA and CM varied by deployment status and time in service. CA and CM had higher risk if never or previously deployed, but occupation was unrelated to suicide attempt among those currently deployed. While there was a substantial difference in standardized risk in never deployed CM $(801 / 100,000$ PY) and CA $(601 / 100,000 \mathrm{PY})$, there was virtually no difference in previously deployed (352 and 358/100,000 PY, respectively) [44].

The odds of suicide attempt were higher for CM than $\mathrm{CA}$ and $\mathrm{AO}$ during the first year of service. First-year $\mathrm{CM}$ had the highest standardized risk of all occupations across deployment status and time in service (1313/ 100,000 PY). Monthly hazard rates during the first year of service suggest that $\mathrm{CA}, \mathrm{CM}$, and $\mathrm{AO}$ have different patterns of risk during training. While all soldiers demonstrated rapidly increasing risk from the first to second month of service, the patterns deviated thereafter (approximately the end of basic training). First-year risk among CA was bimodal, whereas risk for $\mathrm{CM}$ remained elevated until the latter half of the first year. Trainingrelated stressors may be particularly difficult to manage for those with pre-existing vulnerabilities, such as the considerable proportion of new soldiers who report a pre-enlistment history of suicidal behavior and mental disorders $[45,46]$.

After basic training $\mathrm{CM}$ undergo advanced training with high performance demands. A previous study found that mental health symptoms, including suicide ideation, increased over the course of CM training, and were associated with female gender and lower education [47] Although about $24 \%$ of CM in our sample were females and all CA soldiers were male, we found that the differential risk between first-year $\mathrm{CM}$ and $\mathrm{CA}$ persisted in males, suggesting that CM-CA differences are not due to gender composition. The proportion of soldiers with less than a high school education was substantially less for CM (9.8\%) than CA (17.8\%). Future research should examine the timing and relationships between lower education, poor training performance, and risk of suicide attempt among CM.

This study has five noteworthy limitations. First, the suicide attempt data are from administrative records. Although perhaps including the most serious cases, these records are subject to errors in clinician diagnosis or medical coding, and would not capture attempts that did not result in medical treatment. Second, our findings may not generalize to other periods of the Iraq and Afghanistan wars, or to other military conflicts. Third, we focused on a specific subset of occupations, but alternative categorizations are possible $[48,49]$. In particular, there are a large number of occupations that fall under CA but are not as directly engaged in combat as a primary job function, e.g., combat engineers, which have elevated suicide deaths relative to the entire Army [13]. The organization of military occupations is not static, but changes over time based on the Army's needs and strategic decisions $[35,36]$. Fourth, we were not able to determine the degree to which the experiences and day-to-day responsibilities of individual soldiers corresponded to their assigned occupational code. Most significantly, these administrative data did not allow assessment of combat exposure. While all occupations considered have a high likelihood of direct combat exposure, actual exposure will vary. Finally, differences across deployment status and time in service are not evidence of within-person changes in suicide attempt risk over time, as the composition of these groups is affected by the non-random nature of deployment and Army retention and attrition [50]. 


\section{Conclusions}

Our findings suggest that occupation may assist in identifying the sub-populations and timing of elevated risk for suicide attempt in the U.S. Army, but the individual risk associated with occupation remains modest. Although we found that combat roles are generally associated with elevated risk, the importance of occupation begins during enlistment. Soldiers often choose their career field, but the Army also assigns occupations based on a soldier's aptitude or performance; therefore soldiers with the same occupation may share similar characteristics (e.g., backgrounds, traits, abilities) that could influence adjustment and mental health [51-55]. To distinguish the extent to which occupational stressors uniquely contribute to suicide risk, it is important for future studies to parse out the effects of individual characteristics that predict career selection, exposures, resilience, and suicide risk. It is also important for future studies to consider how access to lethal means, mental health stigma, and help-seeking behavior vary across occupations. This may be possible in future Army STARRS analyses using longitudinal follow-up surveys and new administrative data systems with potentially important predictors [56].

\section{Additional file}

Additional file 1: Contains tables with additional methodological information and statistical results. (PDF $1868 \mathrm{~kb}$ )

\section{Abbreviations \\ AFMETS: Armed Forces Medical Examiner Tracking System; AO: all other (referring to all other occupations); CA: combat arms; Cl: confidence interval; CM: combat medic; CTS: Contingency Tracking System; DCIPS: Defense Casualty Information Processing System; DEERS: Defense Enrollment Eligibility Reporting System; DMDC: Defense Manpower Data Center; DOD: Department of Defense; DODSER: Department of Defense Suicide Event Report; HADS: Historical Administrative Data Study; ICD-9- CM: International Classification of Diseases, Ninth Revision-Clinical Modification; MDR: Military Health System Data Repository; MOS: military occupational specialty; $\mathrm{NIH}$ : National Institutes of Health; NIMH: National Institute of Mental Health; OR: odds ratio; Pop \%: percent of the population; PY: person-years; SAS: Statistical Analysis System; SF: special forces; SRE: standardized risk estimate; STARRS: Study to Assess Risk and Resilience in Servicemembers; TMDS: Theater Medical Data Store; \\ TRAC2ES: Transportation Command Regulating And Command And Contro Evacuation System; US: United States; USAPHC: United States Army Public Health Command; VA: Veterans Affairs}

\section{Acknowledgments}

The Army STARRS Team consists of Co-Principal Investigators: Robert J. Ursano, MD (Uniformed Services University of the Health Sciences) and Murray B. Stein, MD, MPH (University of California San Diego and VA San Diego Healthcare System).

Site Principal Investigators: Steven Heeringa, PhD (University of Michigan), James Wagner, PhD (University of Michigan) and Ronald C. Kessler, PhD (Harvard Medical School).

Army liaison/consultant: Kenneth Cox, MD, MPH (USAPHC (Provisional)). Other team members: Pablo A. Aliaga, MS (Uniformed Services University of the Health Sciences); COL David M. Benedek, MD (Uniformed Services University of the Health Sciences); Laura Campbell-Sills, PhD (University of California San Diego); Carol S. Fullerton, PhD (Uniformed Services University of the Health Sciences); Nancy Gebler, MA (University of Michigan); Robert K. Gifford, PhD (Uniformed Services University of the Health Sciences); Paul E. Hurwitz, MPH (Uniformed Services University of the Health Sciences); Sonia Jain, PhD (University of California San Diego); Tzu-Cheg Kao, PhD (Uniformed Services University of the Health Sciences); Lisa Lewandowski-Romps, PhD (University of Michigan); Holly Herberman Mash, PhD (Uniformed Services University of the Health Sciences); James E. McCarroll, PhD, MPH (Uniformed Services University of the Health Sciences); James A. Naifeh, PhD (Uniformed Services University of the Health Sciences); Tsz Hin Hinz Ng, MPH (Uniformed Services University of the Health Sciences); Matthew K. Nock, PhD (Harvard University); Nancy A. Sampson, BA (Harvard Medical School); CDR Patcho Santiago, MD, MPH (Uniformed Services University of the Health Sciences); LTC Gary H. Wynn, MD (Uniformed Services University of the Health Sciences); and Alan M. Zaslavsky, PhD (Harvard Medical School).

\section{Funding}

Army STARRS was sponsored by the Department of the Army and funded under cooperative agreement number U01MH087981 (2009-2015) with the U.S.

Department of Health and Human Services, National Institutes of Health, National Institute of Mental Health (NIH/NIMH). Subsequently, STARRS-LS was sponsored and funded by the Department of Defense (USUHS grant number HU0001-152-0004). The contents are solely the responsibility of the authors and do not necessarily represent the views of the Department of Health and Human Services, $\mathrm{NIMH}$, or the Department of the Army, or the Department of Defense.

\section{Availability of data and materials}

For information on data availability, please contact the Uniformed Services University of the Health Sciences Institutional Review Board, 4301 Jones Bridge Road, Bethesda, MD 20814.

\section{Authors' contributions}

CSF, HHM, JAN, MBS, MS, RCK, RJU, and SGH contributed to the study concept and design. CSF, GHW, HHM, HMD, JAN, JEM, MBS, MS, NAS, PAA, SGH, RCK, RJU, THHN, and TK were responsible for the acquisition, analysis, or interpretation of the data. CSF, HHM, JAN, PAA, RCK, THHN, and RJU were involved in drafting the manuscript. CSF, GHW, HMD, HHM, JAN, JEM, MBS, MS, NAS, PAA, SGH, RCK, RJU, THHN, and TK contributed to critical revision of the manuscript for important intellectual content. CSF, GHW, HHM, HMD, JAN, JEM, MBS, MS, NAS, PAA, SGH, RCK, RJU, THHN, and TK provided administrative, technical, and material support. All authors read and approved the final manuscript.

\section{Competing interests}

Kessler has been a consultant over the past three years for J \& J Wellness \& Prevention, Inc., Lake Nona Institute, Ortho-McNeil Janssen Scientific Affairs, SanofiAventis Groupe, Shire US Inc., and Transcept Pharmaceuticals Inc. and has had research support for his epidemiological studies over this time period from EPI-Q, and Sanofi-Aventis Groupe, and Walgreens Co. Kessler owns 25\% share in DataStat, Inc. Stein has been a consultant for Actelion Pharmaceuticals, Healthcare Management Technologies, Janssen Pharmaceuticals, Pfizer, Remedy Therapeutics and Tonix Pharmaceuticals. The remaining authors report nothing to disclose.

\section{Consent for publication}

Not applicable.

\section{Ethics approval and consent to participate}

This component of Army STARRS was approved by the Institutional Review Boards of the Uniformed Services University of the Health Sciences for the Henry M. Jackson Foundation (the primary grantee), the University of Michigan Institute for Social Research (site of the Army STARRS Data Enclave), University of California, San Diego, and Harvard Medical School, which determined that the present study did not constitute human participant research because it relies entirely on deidentified secondary data.

\section{Publisher's Note}

Springer Nature remains neutral with regard to jurisdictional claims in published maps and institutional affiliations.

\section{Author details}

${ }^{1}$ Center for the Study of Traumatic Stress, Department of Psychiatry, Uniformed Services University of the Health Sciences, 4301 Jones Bridge 
Road, Bethesda, MD 20814, USA. ${ }^{2}$ Department of Health Care Policy, Harvard Medical School, 180 Longwood Avenue, Boston, MA 02115, USA. ${ }^{3}$ Department of Preventive Medicine and Biostatistics, Uniformed Services University of the Health Sciences, 4301 Jones Bridge Road, Bethesda, MD 20814, USA. ${ }^{4}$ Office of Clinical and Population Epidemiology Research, Division of Services and Intervention Research, National Institute of Mental Health, 6001 Executive Blvd, Room 7137, MSC 9635, Bethesda, MD 20892, USA. ${ }^{5}$ Institute for Social Research, University of Michigan, 426 Thompson Street, Ann Arbor, MI 48106-1248, USA. ${ }^{6}$ Departments of Psychiatry and Family Medicine \& Public Health, University of California San Diego, 8939 Villa La Jolla Drive, Suite 200, La Jolla, California 92037, USA. ’VA San Diego Healthcare System, 8810 Rio San Diego Drive, San Diego, CA 92108, USA.

Received: 23 February 2017 Accepted: 5 May 2017 Published online: 25 May 2017

\section{References}

1. Schoenbaum M, Kessler RC, Gilman SE, Colpe LJ, Heeringa SG, Stein MB, Ursano RJ, Cox KL. Predictors of suicide and accident death in the Army study to assess risk and resilience in Servicemembers (Army STARRS). JAMA Psychiatry. 2014;71(5):493-503.

2. Ursano RJ, Kessler RC, Heeringa SG, Cox KL, Naifeh JA, Fullerton CS, Sampson NA, Kao T-C, Aliaga PA, Vegella P et al: Nonfatal suicidal behaviors in U.S. Army administrative records, 2004-2009: Results from the Army study to assess risk and resilience in Servicemembers (Army STARRS). Psychiatry 2015, 78:1-21.

3. Black SA, Gallaway MS, Bell MR, Ritchie EC. Prevalence and risk factors associated with suicides of army soldiers 2001-2009. Mil Psychol. 2011;23: 433-51.

4. Warner $\mathrm{CH}$, Breitbach JE, Appenzeller GN, Yates V, Grieger T, Webster WG. Division mental health in the new brigade combat team structure: part I. Predeployment and deployment Mil Med. 2007;172(9):907-11.

5. Warner $\mathrm{CH}$, Breitbach JE, Appenzeller GN, Yates V, Grieger T, Webster WG. Division mental health in the new brigade combat team structure: part II. Redeployment and postdeployment Mil Med. 2007;172(9):912-7.

6. Appenzeller GN, Warner CH, Grieger T. Postdeployment health reassessment: a sustainable method for brigade combat teams. Mil Med. 2007;172(10):1017-23.

7. Ramchand R, Acosta J, Burns RM, Jaycox LH, Pernin CG. The war within: preventing suicide in the U.S. military. In. Santa Monica, CA: RAND Corporation; 2011.

8. Gilman SE, Bromet EJ, Cox KL, Colpe LJ, Fullerton CS, Gruber MJ, Heeringa SG, Lewandowski-Romps L, Millikan-Bell AM, Naifeh JA, et al. Sociodemographic and career history predictors of suicide and suicide mortality in the United States Army 2004-2009. Psychol Med. 2014;44(12):2579-92.

9. Reger MA, Smolenski DJ, Skopp NA, Metzger-Abamukang MJ, Kang HK, Bullman TA, Perdue S, Gahm GA. Risk of suicide among US military service members following operation enduring freedom or operation Iraqi freedom deployment and separation from the US military. JAMA Psychiatry. 2015; 72(6):561-9.

10. Leard Mann CA, Powell TM, Smith TC, Bell MR, Smith B, Boyko EJ, Hooper TI, Gackstetter GD, Ghamsary M, Hoge CW. Risk factors associated with suicide in current and former U.S. military personnel. J Am Med Assoc. 2013;310(5):496-506.

11. Shen YC, Cunha JM, Williams TV. Time-varying associations of suicide with deployments, mental health conditions, and stressful life events among current and former US military personnel: a retrospective multivariate analysis. Lancet Psychiatry. 2016;3:1039-48.

12. Bryan CJ, Griffith JH, Pace BT, Hinkson K, Bryan AO, Clemans TA, Imel ZE. Combat exposure and risk for suicidal thoughts and behaviors among military personnel and veterans: a systematic review and meta-analysis. Suicide Life Threat Behav. 2015;45(5):633-49.

13. Kessler RC, Stein MB, Bliese PD, Bromet EJ, Chiu WT, Cox KL, Colpe LJ, Fullerton CS, Gilman SE, Gruber MJ, et al. Occupational differences in U.S. Army suicide rates. Psychol Med. 2015;45(15):3293-304.

14. Trofimovich L, Reger MA, Luxton DD, Oetjen-Gerdes LA. Suicide risk by military occupation in the DoD active component population. Suicide Life Threat Behav. 2013;43(3):274-8.

15. Kok BC, Herrell RK, Thomas JL, Hoge CW. Posttraumatic stress disorder associated with combat service in Iraq or Afghanistan: reconciling prevalence differences between studies. J Nerv Ment Dis. 2012;200(5):444-50.
16. Sundin J, Fear NT, Iversen A, Rona RJ, Wessely S. PTSD after deployment to Iraq: conflicting rates, conflicting claims. Psychol Med. 2010;40(3):367-82.

17. Trofimovich L, Reger MA, Luxton DD, Oetjen-Gerdes LA. Suicide risk by military occupation in the DoD active component population. Suicide \& lifethreatening behavior. 2013;43(3):274-8.

18. Morgan CA III, Southwick SM, Hazliett G, Dial-Ward M. Baseline dissociation and prospective success in special forces assessment and selection. Psychiatry (Edgmont). 2008:5(7):53-8.

19. Bartone PT, Roland RR, Picano JJ, Williams TJ: Psychological hardiness predicts success in U.S. Army special forces candidates. Int J Sel Assess 2008, 16:78-81.

20. Vythilingam M, Nelson EE, Scaramozza M, Waldeck T, Hazlett G, Southwick SM, Pine DS, Drevets W, Charney DS, Ernst M. Reward circuitry in resilience to severe trauma: an fMRI investigation of resilient special forces soldiers. Psychiatry Res Neuroimaging. 2009;172:75-7.

21. Hanwella R, de Silva V. Mental health of special forces personnel deployed in battle. Soc Psychiatry Psychiatr Epidemiol. 2012;47:1343-51

22. Pappas CG. The ranger medic. Mil Med. 2001;166(5):394-400.

23. Chapman PL, Cabrera D, Varela-Mayer C, Baker M, Lin C-D, Mayer P. Training, deployment preparation, and combat experiences of deployed health care personnel: key findings from deployed U. S. Army combat medics assigned to line units. Mil Med. 2012;177(3):270-7.

24. Elnitsky CA, Chapman PL, Thurman RM, Pitts BL, Figley C, Unwin B. Gender differences in combat medic mental health services utilization, barriers, and stigma. Mil Med. 2013;178(7):775-84.

25. Ursano RJ, Kessler RC, Stein MB, Naifeh JA, Aliaga PA, Fullerton CS, Wynn GH, Vegella PL, Ng TH, Zhang BG, et al. Risk factors, methods, and timing of suicide attempts among U.S. Army soldiers. JAMA Psychiatry. 2016;73(7):741-9.

26. Ursano RJ, Kessler RC, Stein MB, Naifeh JA, Aliaga PA, Fullerton CS, Sampson NA, Kao T-C, Colpe LJ, Schoenbaum M, et al. Suicide attempts in the U.S. Army during the wars in Afghanistan and Iraq. JAMA Psychiatry 2015. 2004-2009;72(9):917-26

27. Ursano RJ, Colpe LJ, Heeringa SG, Kessler RC, Schoenbaum M, Stein MB. The Army study to assess risk and resilience in Servicemembers (Army STARRS). Psychiatry. 2014;72(2):107-19.

28. Larson GE, Highfill-McRoy RM, Booth-Kewley S. Psychiatric diagnoses in historic and contemporary military cohorts: combat deployment and the healthy warrior effect. Am J Epidemiol. 2008;167(11):1269-76.

29. Wilson J, Jones M, Fear NT, Hull L, Hotopf M, Wessely S, Rona RJ. Is previous psychological health associated with the likelihood of Iraq war deployment? An investigation of the "healthy warrior effect". Am J Epidemiol. 2009;169(11):1362-9.

30. Kessler RC, Colpe LJ, Fullerton CS, Gebler N, Naifeh JA, Nock MK, Sampson NA, Schoenbaum M, Zaslavsky AM, Stein MB, et al. Design of the Army Study to assess risk and resilience in Servicemembers (Army STARRS). Int J Methods Psychiatr Res. 2013;22(4):267-75.

31. Willett JB, Singer JD. Investigating onset, cessation, relapse, and recovery: why you should, and how you can, use discrete-time survival analysis to examine event occurrence. J Consult Clin Psychol. 1993;61(6):952-65.

32. Schlesselman JJ. Case-control studies: design, conduct, analysis. New York, NY: Oxford University Press; 1982.

33. Gahm GA, Reger MA, Kinn JT, Luxton DD, Skopp NA, Bush NE. Addressing the surveillance goal in the National Strategy for suicide prevention: the Department of Defense Suicide Event Report. Am J Public Health. 2012; 102(Suppl 1):S24-8.

34. Walkup JT, Townsend L, Crystal S, Olfson M. A systematic review of validated methods for identifying suicide or suicidal ideation using administrative or claims data. Pharmacoepidemiol Drug Saf. 2012;21(Suppl 1):174-82.

35. Kirin SJ, Winkler JD. The Army military occupational specialty database Santa Monica. CA: RAND Corporation; 1992.

36. M. L, S. N, J. TH, J.H. K: Military occupational specialties: Change and consolidation. Santa Monica, CA.: RAND Corporation; 2001.

37. SAS Institute Inc.: SAS ${ }^{\otimes} 9.3$ Software. Cary, NC: SAS Institute Inc:; 2011.

38. Roalfe AK, Holder RL, Wilson S. Standardisation of rates using logistic regression: a comparison with the direct method. BMC Health Serv Res. 2008;8:275.

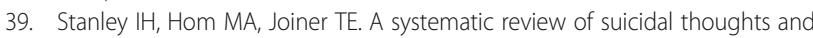
behaviors among police officers, firefighters, EMTs, and paramedics. Clin Psychol Rev. 2016;44:25-44.

40. U.S. Department of Defense: Special Operations, Joint Publication 3-05. Washington, DC: U.S. Government Publishing Office; 2014.

41. Manning FJ, Fullerton TD. Health and well-being in highly cohesive units of the U.S. Army. J Appl Soc Psychol. 1988;18(6):503-19. 
42. Dean P, McNeil J. Breaking the stigma of behavioral healthcare. Special Warfare. 2012;25(2):7-9.

43. Joint Special Operations University. Special operations research topics 2016. Tampa. FL: Joint Special Operations University Press; 2015.

44. Pitts BL, Chapman P, Safer MA, Unwin B, Figley CR, Russell DW. Killing versus witnessing trauma: implications for the development of PTSD in combat medics. Mil Psychol. 2014;25(6):537-44.

45. Rosellini AJ, Heeringa SG, Stein MB, Ursano RJ, Chiu WT, Colpe L, Fullerton CS, Gilman SE, Hwang I, Naifeh JA, et al. Lifetime prevalence of DSM-IV mental disorders among new soldiers in the U.S. Army: results from the Army study to assess risk and resilience in Servicemembers (Army STARRS). Depress Anxiety. 2015;32:13-24.

46. Ursano RJ, Heeringa SG, Stein MB, Jain S, Raman R, Sun X, Chiu WT, Colpe $\sqcup$, Fullerton CS, Gilman SE, et al. Prevalence and correlates of suicidal behavior among new soldiers in the US Army: results from the Army study to assess risk and resilience in Servicemembers (Army STARRS). Depress Anxiety. 2015:32:3-12.

47. Robinson ME, Teyhen DS, Wu SS, Dugan JL, Wright AC, Childs JD, Yang G, George SZ. Mental health symptoms in combat medic training: a longitudinal examination. Mil Med. 2009;174(6):572-7.

48. Niebuhr DW, Krampf RL, Mayo JA, Blandford CD, Levin LI, Cowan DN. Risk factors for disability retirement among healthy adults joining the U.S. Army. Mil Med. 2011;176(2):170-5

49. Gubata ME, Piccirillo AL, Packnett ER, Cowan DN. Military occupation and deployment: descriptive epidemiology of active duty U.S. Army men evaluated for a disability discharge. Mil Med. 2013;178(7):708-14.

50. Ireland RR, Kress AM, Frost LZ. Association between mental health conditions diagnosed during initial eligibility for military health care benefits and subsequent deployment, attrition, and death by suicide among active duty service members. Mil Med. 2012;177(10):1149-56.

51. MacLean A, Parsons NL. Unequal risk: combat occupations in the volunteer military. Sociol Perspect. 2010;53(3):iii-V.

52. Morey LC, Lowmaster SE, Coldren RL, Kelly MP, Parish RV, Russell ML. Personality assessment inventory profiles of deployed combat troops: an empirical investigation of normative performance. Psychol Assess. 2011; 23(2):456-62.

53. Montes KS, Weatherly JN. The relationship between personality traits and military enlistment: an exploratory study. Military Behavioral Health. 2013; 2(1):98-104.

54. Neria Y, Solomon Z, Ginzburg K, Dekel R. Sensation seeking, wartime performance, and long-term adjustment among Israeli war veterans. Pers Individ Dif. 2000:29:921-32

55. Parmak M, Mylle JJ, Euwema MC: Sensation seeking and perceived need for structure moderate soldiers' well-being before and after operational deployment. Military Behavioral Health 2014, 2(75-81).

56. Niebuhr DW, Gubata ME, Oetting AA, Weber NS, Feng X, Cowan DN: Personality assessment questionnaire as a pre-accession screen for risk of mental disorders and early attrition in US Army recruits. Psychol Serv 2013, 10:378-385

\section{Submit your next manuscript to BioMed Central and we will help you at every step:}

- We accept pre-submission inquiries

- Our selector tool helps you to find the most relevant journal

- We provide round the clock customer support

- Convenient online submission

- Thorough peer review

- Inclusion in PubMed and all major indexing services

- Maximum visibility for your research

Submit your manuscript at www.biomedcentral.com/submit 